\title{
Studi Korelasi Program Pelatihan Tatarias Kecantikan dengan Sikap Wirausaha Warga Belajar di Lembaga Pendidikan Nonformal
}

\author{
Ida Rosita, M. A. Rizka \\ Program Studi Pendidikan Luar Skeolah, FIPP UNDIKMA \\ *Corresponding Author. Email: m.ariefrizka@undikma.ac.id
}

\begin{abstract}
This study aims to analyze the correlation between the bridal makeup training program and the entrepreneurial attitude of students at the nonformal education institution of LKP Kartika. This study uses a correlational method with a quantitative approach. This research is a population study with 12 trainees as respondents. Data collection techniques using questionnaires and documentation. The data analysis method used is product moment correlation analysis. The results of the rxy calculation obtained in this study are 0.619 , while the value of $r$ Product Moment in the table with a significance level of 5\% and $\mathrm{N}=12$ is 0.576 . So that the calculated $\mathrm{r}$ value is greater than the Product Moment $r$ value in the table $(0.619>0.576)$ with the conclusion that there is a relationship between the bridal make-up training program and the entrepreneurial attitude of citizens studying at non-formal education institutions LKP Kartika.
\end{abstract}

Abstrak: Penelitian ini bertujuan untuk menganalisis korelasi antara program pelatihan tata rias pengantin dengan sikap wirausaha warga belajar di lembaga pendidikan nonformal LKP Kartika. Penelitian ini menggunakan metode korelasional dengan pendekatan kuantitatif. Penelitian ini merupakan studi populasi dengan responden peserta pelatihan berjumlah 12 orang. Teknik pengambilan data menggunakan kuesioner dan dokumentasi. Metode analisis data yang digunakan adalah analisis korelasi product moment. Hasil perhitungan rxy yang diperoleh dalam penelitian ini adalah 0,619 , sedangkan nilai r Product Moment dalam tabel dengan taraf signifikansi 5\% dan $\mathrm{N}=12$ adalah 0,576. Sehingga nilai $r$ hitung lebih besar dari pada nilai $r$ Product Moment dalam tabel $(0,619>0,576)$ dengan kesimpulan ada hubungan antara program pelatihan tatarias pengantin dengan sikap wirausaha warga belajar di di lembaga pendidikan nonformal LKP Kartika.

\section{Article History}

Received: 21-06-2021

Revised: 07-07-2021

Accepted: 21-08-2021

Published: 05-10-2021

\section{Key Words:}

Training Program,

Entrepreneurial Attitude,

Nonformal Education.

\section{Sejarah Artikel}

Diterima: 21-06-2021

Direvisi: 07-07-2021

Disetujui: 21-08-2021

Diterbitkan: 05-10-2021

\section{Kata Kunci:}

Program Pelatihan, Sikap

Wirausaha, Pendidikan

Nonformal.

How to Cite: Rosita, I., \& Rizka, M. (2021). Studi Korelasi Program Pelatihan Tatarias Kecantikan dengan Sikap Wirausaha Warga Belajar di Lembaga Pendidikan Nonformal. Jurnal Paedagogy, 8(4), 522-528. doi:https://doi.org/10.33394/jp.v8i4.4056

https://doi.org/10.33394/jp.v8i4.4056

This is an open-access article under the CC-BY-SA License.

\section{Pendahuluan}

Pendidikan nonformal adalah salah satu jalur pendidikan untuk mencerdaskan kehidupan bangsa dengan tujuan memberikan kesempatan belajar seluas-luasnya bagi masyarakat. Sihombing dalam Anjani \& Darojatun (2019) menyebutkan bahwa tujuan pendidikan luar sekolah memberikan kesempatan belajar yang seluas-luasnya bagi masyarakat yang karena berbagai faktor seperti kesulitan ekonomi, sosial dan lingkungan yang kurang mendukung tidak mendapat kesempatan untuk mengikuti pendidikan melalui jalur pendidikan sekolah. Pendidikan nonformal merupakan salah satu alternatif yang dapat memenuhi kebutuhan bagi masyarakat yang tidak memiliki kesempatan memperoleh pendidikan formal, atau anak-anak yang putus sekolah maupun lulusan pendidikan formal yang ingin menambah pendidikannya dengan berbagai keterampilan (Rizka \& Zulkipli, 2017; Winandi \& Rizka, 2018), sesuai dengan UU RI No. 20 Tahun 2003 pasal 26 ayat (1) 
mengenai pendidikan nonformal yang menerangkan bahwa: "pendidikan nonformal diselenggarakan bagi masyarakat yang memerlukan layanan pendidikan yang berfungsi sebagai pengganti, penambah dan/atau pelengkap pendidikan formal dalam rangka mendukung pendidikan sepanjang hayat".

Berkaitan dengan pendidikan Nonformal sering dikeluhkan kurang tertanamnya jiwa kewirausahan pada warga belajar. Seperti diungkapkan Ciputra (2007) yang mengharapkan lembaga pendidikan mampu menciptakan generasi muda yang memiliki jiwa kewirausahaan sehingga mereka bisa mengubah rongsokan menjadi emas. Selanjutnya Ciputra (Nurdin, 2016) menambahkan bahwa kebanyakan generasi muda tidak dibesarkan dalam budaya wirasusaha sehingga ketika dewasa memiliki pola pikir untuk mencari kerja bukan mencipta kerja.

Profesi tata rias kecantikan menjadi sebuah peluang kerja yang sangat menjanjikan, keahlian untuk menjadi penatarias kecantikan bisa didapatkan dengan cara mengikuti program pelatihan di lembaga pendidikan nonformal. Pendidikan nonformal memberikan kesempatan belajar bagi semua lapisan masyarakat yang membutuhkan peningkatan keterampilan yang diselenggarakan oleh masyarakat, baik perorangan maupun lembaga. Materi pelatihan dan keterampilan pada bidang kecantikan terdiri dari: pelatihan tata kecantikan rambut, tata rias wajah atau make up, tata kecantikan kulit, spa, dan tata rias pengantin. Pelatihan tata rias pengantin merupakan salah satu jenis pelatihan yang banyak diminati oleh masyarakat.

Lembaga kursus dan pelatihan (LKP) Kartika merupakan salah satu lembaga pendidikan nonformal yang berkembang dengan baik. Tujuan penyelenggaraan kursus LKP Kartika sebagaimana tercantum dalam rumusan tujuan pendidikan dan keterampilan yaitu mewujudkan warga belajar yang terampil dan mampu mengintegrasikan pengetahuannya di lingkungan masyarakat seoptimal mungkin. Dalam konsep ekonomi lulusan diharapkan dapat mengisi kebutuhan tenaga kerja yang kompetitif secara nasional maupun internasional serta berkemampuan untuk membangun usaha mandiri yang dapat membantu untuk pengembangan struktur perekonomian daerah yang tangguh serta dapat melestarikan budaya masyarakat.

Kompetensi yang diharapkan dari pelatihan tata rias kecantikan adalah warga belajar mampu melakukan tata rias dengan baik dan benar agar sesuai dengan apa yang di inginkan. Warga belajar yang menempuh proses pelatihan tata rias kecantikan dengan optimal dan sungguh-sungguh diharapkan dapat memberikan perubahan yang positif berupa pengetahuan, sikap, dan keterampilan yang disebut hasil pelatihan. Hasil pelatihan tata rias kecantikan sesuai dengan kompetensi pembelajaran, diharapkan dapat memberikan manfaat sebagai bekal kesiapan dalam mengikuti uji kompetensi rias pengantin.

Fakta dilapangan mengatakan bahwa ada sebagian besar warga belajar yang telah memiliki pengetahuan serta keterampilan tata rias akan tetapi ilmu yang mereka dapat belum mereka implementasikan secara langsung, oleh karena itu masih banyaknya pengangguran yang ada dikarenakan kurangnya mitra kerja antara lembaga kursus dengan lembaga-lembaga lainya disamping sikap wirausaha lulusan pelatihan yang masih minim (Tamba et al., 2020). Adapun tujuan penelitian ini adalah untuk menganalisis korelasi antara program pelatihan tata rias kecantikan dengan sikap wirausaha warga belajar di lembaga pendidikan nonformal LKP Kartika. 


\section{Metode Penelitian}

Metode penelitian ini menggunakan metode korelasional dengan pendekatan kuantitatif. Dalam penelitian ini tidak menggunakan sampel, tetapi menggunakan studi populasi karena peserta pelatihan tersebut kurang dari 100 orang yaitu hanya berjumlah 12 orang. Instrumen penelitian adalah suatu alat yang digunakan mengukur fenomena alam maupun sosial yang diamati (Sugiyono, 2014; Arikunto, 2010; Sumiyanty et al., 2018; Syanjar et al., 2021). Instrumen yang digunakan dalam penelitian ini adalah angket dan dokumentasi. Sedangkan teknik analisis data penelitian ini menggunakan analisis korelasi product moment.

\section{Hasil Penelitian dan Pembahasan}

Sebelum penelitian ini dilakukan, terlebih dahulu dilakukan uji validitas dan reliabilitas instrumen (angket) penelitian. Uji validitas digunakan untuk mengetahui kelayakan butir-butir dalam suatu daftar pertanyaan dalam mendefinisikan suatu variabel. Sedangkan uji reliabilitas (keandalan) merupakan ukuran suatu kestabilan dan konsistensi respoden dalam menjawab hal yang berkaitan dengan kontruk-kontruk pertanyaan yang merupakan dimensi suatu variabel dan disusun dalam suatu bentuk kuisioner (Sujarweni, 2008).

Hasil uji coba instrumen dilakukan pada 12 responden diperoleh 15 soal yang valid dan 5 soal yang tidak valid. Suatu instrumen/angket atau bahan tes dinyatakan valid atau dianggap memenuhi syarat jika harga koefisien jika $r$ tabel $>0,444$. Jika alat ukur telah dinyatakan valid, selanjutnya reliabelitas alat ukur tersebut diuji. Nilai Cronbach's Alpha yang dapat diterimah $>0,60$. Pada penelitian ini, teknik pengukuran reliabilitas yang digunakan adalah tehnik Cronbach's. Pengujian Validilitas dan reliabilitas dilakukan dengan bantuan pengolah data SPSS. Hasil uji validitas dan reliabilitas terhadap butir pertanyaan pada variabel komunikasi persuasif dapat dilihat pada tabel di bawah ini :

\section{Tabel 1. Uji Validitas dan Reliabilitas Variabel}

Item-Total Statistics

\begin{tabular}{|c|c|c|c|c|}
\hline & $\begin{array}{l}\text { Scale Mean if } \\
\text { Item Deleted }\end{array}$ & $\begin{array}{c}\text { Scale Variance if } \\
\text { Item Deleted }\end{array}$ & $\begin{array}{l}\text { Corrected Item- } \\
\text { Total Correlation }\end{array}$ & $\begin{array}{l}\text { Cronbach's Alpha if } \\
\text { Item Deleted }\end{array}$ \\
\hline $\mathrm{p} 1$ & 51.32 & 32.060 & 419| & .647 \\
\hline p2 & 51.84 & 32.473 & .499| & .672 \\
\hline p3 & 50.92 & 31.910 & .503 & .636 \\
\hline p4 & 51.56 & 32.840 & .434| & .686 \\
\hline p5 & 50.80 & 30.333 & .594| & .621 \\
\hline p6 & 50.56 & 32.423 & .468| & .659 \\
\hline p7 & 50.68 & 35.060 & .300 & .67 \\
\hline p8 & 51.00 & 32.167 & .453 & .64 \\
\hline p9 & 51.88 & 30.777 & .487| & .646 \\
\hline p10 & 51.80 & 31.583 & |469| & .671 \\
\hline p11 & 51.08 & 32.910 & .468| & .659 \\
\hline p12 & 51.76 & 32.273 & .485 & .677 \\
\hline p13 & 50.76 & 34.190 & $.507 \mid$ & .66 \\
\hline p14 & 51.32 & 36.477 & -.041- & .687 \\
\hline p15 & 51.36 & 30.657 & .544 & .62 \\
\hline p16 & 51.24 & 32.190 & .450 & .68 \\
\hline p17 & 51.32 & 30.243 & .479| & .660 \\
\hline p18 & 51.24 & 31.107 & $.605 \mid$ & .62 \\
\hline
\end{tabular}




\begin{tabular}{|l|l|l|l|}
$\mathrm{p} 19$ & 51.72 & 31.210 & .509 \\
$\mathrm{p} 20$ & 51.08 & 35.827 & .002
\end{tabular} \mid

Berdasarkan hasil uji coba angket Variabel program pelatihan tata rias kecantikan dianalisis dengan menggunakan rumus korelasi product-moment dengan menggunakan angka kasar dan didapatkan bahwa 15 butir soal valid dan 5 butir soal tidak valid dari 20 butir soal yaitu soal nomor 1,4,7,14 dan 20 sehingga pertanyaan tersebut ditiadakan.

\section{Tabel 2. Uji Reliability Statistics Variabel X}

Reliability Statistics

\begin{tabular}{|l|l|}
\hline Cronbach's Alpha & N of Items \\
\hline .673 & 20 \\
\hline
\end{tabular}

Selanjutnya dilihat hasil reliabilitas angket penelitian menggunakan rumus Alpha Cronbach's dengan dibantu oleh program SPSS. Hasil perbitugan dapat dilihat pada tabel berikut, Uji reliabelitas dapat dilihat pada nilai Cronbach's Alpha, jika nilai Cronbach's Alpha > 0,60 maka konstruk pertanyaan yang merupakan dimensi variabel adalaha reliabel. Nilai Cronbach's Alpha adalah 0,673, jadi di atas 0,60 maka reliabel.

Tabel 3. UjiAnalisis Validitas dan Reliabilitas Variabel Sikap Wirausaha (Y) Iterasi

\section{Pertama}

Item-Total Statistics

\begin{tabular}{|c|c|c|c|c|}
\hline & $\begin{array}{c}\text { Scale Mean if } \\
\text { Ite Deleted }\end{array}$ & $\begin{array}{l}\text { Scale Variance if } \\
\text { Item Deleted }\end{array}$ & $\begin{array}{l}\text { Corrected Item- } \\
\text { Total Correlation }\end{array}$ & $\begin{array}{l}\text { Cronbach's Alpha } \\
\text { if Item Deleted }\end{array}$ \\
\hline P1 & 53.32 & 50.727 & .465 & .756 \\
\hline $\mathrm{P} 2$ & 52.40 & 47.583 & .558 & .746 \\
\hline P3 & 52.84 & 53.307 & .125 & .777 \\
\hline P4 & 52.76 & 50.190 & .484 & .759 \\
\hline P5 & 52.76 & 48.440 & $.624 \mid$ & .745 \\
\hline P6 & $52.44 \mid$ & 48.340 & $.474 \mid$ & .764 \\
\hline P7 & 52.48 & 50.760 & .466 & .769 \\
\hline P8 & 52.28 & 49.543 & $.452 \mid$ & .776 \\
\hline P9 & 52.04 & 47.707 & $.574 \mid$ & .745 \\
\hline P10 & 52.16 & 49.140 & .475| & .753 \\
\hline P11 & 52.44 & 54.673 & .121 & .764 \\
\hline P12 & 53.24 & 48.440 & .512 & .770 \\
\hline P13 & 52.68 & 51.310 & .274 & .767 \\
\hline P14 & 52.80 & 50.750 & .494| & .759 \\
\hline P15 & 52.72 & 49.043 & $.450 \mid$ & .784 \\
\hline P16 & 52.56 & 55.007 & $-.008-$ & .785 \\
\hline P17 & 52.36 & 52.073 & .548 & .737 \\
\hline P18 & 52.68 & 48.643 & .529 & .749 \\
\hline P19 & 52.20 & 55.917 & .323 & .739 \\
\hline $\mathrm{P} 20$ & 52.68 & 48.560 & .526 & .773 \\
\hline
\end{tabular}

Berdasarkan hasil uji coba angket Variabel program pelatihan tata rias pengantin dianalisis dengan menggunakan rumus korelasi product- moment dengan menggunakan angka kasar dan didapatkan bahwa 15 butir soal valid dan 5 butir soal tidak valid dari 20 butir soal yaitu soal nomor 3,11,13,16 dan 19 sehingga pertanyaan tersebut ditiadakan. 


\section{Tabel 4. Uji Reliability statistics Variabel Y Reliability Statistics}

\begin{tabular}{|l|l|}
\hline Cronbach's Alpha & N of Items \\
\hline .772 & 20 \\
\hline
\end{tabular}

Uji reliabelitas dapat dilihat pada nilai Cronbach's Alpha, jika nilai Cronbach's Alpha > 0,60 maka konstruk pertanyaan yang merupakan dimensi variabel adalaha reliabel. Nilai Cronbach's Alpha adalah 0,772, jadi di atas 0,60 maka reliabel.

Data yang terkumpul dalam penelitian ini selanjutnya akan dimasukkan kedalam tabel kerja untuk dianalisis guna menganalisis korelasi antara program pelatihan tata rias kecantikan dengan sikap wirausaha di LKP Kartika. Adapun tabel kerja yang dimaksud adalah sebagai berikut:

Tabel 5. Tabel Kerja Pengujian Hipotesis

\begin{tabular}{|c|c|c|c|c|c|r|r|}
\hline No & $\mathbf{X}$ & $\mathbf{Y}$ & $\mathbf{x}$ & $\mathbf{Y}$ & $\mathbf{x}^{\mathbf{2}}$ & \multicolumn{1}{|c|}{$\mathbf{2}$} & \multicolumn{1}{|c|}{$\mathbf{x . y}$} \\
\hline 1 & 56 & 58 & 2 & 2.2 & 4 & 4.84 & 4.4 \\
\hline 2 & 55 & 58 & 1 & 2.2 & 1 & 4.84 & 2.2 \\
\hline 3 & 57 & 57 & 3 & 1.2 & 9 & 1.44 & 3.6 \\
\hline 4 & 52 & 59 & -2 & 3.2 & 4 & 10.24 & -6.4 \\
\hline 5 & 54 & 56 & 0 & 0.2 & 0 & 0.04 & 0 \\
\hline 6 & 54 & 57 & 0 & 1.2 & 0 & 1.44 & 0 \\
\hline 7 & 51 & 52 & -3 & -3.8 & 9 & 14.44 & 11.4 \\
\hline 8 & 58 & 59 & 4 & 3.2 & 16 & 10.24 & 12.8 \\
\hline 9 & 53 & 57 & -1 & 1.2 & 1 & 1.44 & -1.2 \\
\hline 10 & 53 & 55 & -1 & -0.8 & 1 & 0.64 & 0.8 \\
\hline 11 & 54 & 52 & 0 & -3.8 & 0 & 14.44 & 0 \\
\hline 12 & 50 & 52 & -4 & -3.8 & 16 & 14.44 & 15.2 \\
\hline $\begin{array}{c}\text { N=12 } \\
\text { Nilai }\end{array}$ & $\mathrm{X}=648$ & $\mathrm{Y}=670$ & 0 & 0 & $\mathrm{x}^{2}=61$ & $\mathrm{v}^{2}=78.48$ & $\mathrm{xy}=42,8$ \\
\hline $\begin{array}{c}\text { rata-rata } \\
\text { rata }\end{array}$ & & 55,8 & & & & & \\
\hline
\end{tabular}

Hasil perhitungan rxy yang diperoleh dalam penelitian ini adalah 0,619. Sedangkan nilai $\mathrm{r}$ Product Moment dalam tabel dengan taraf signifikansi 5\% dan $\mathrm{N}=12$ adalah 0,576. Kenyataan ini menunjukkan bahwa nilai $\mathrm{r}$ hitung lebih besar dari pada nilai $\mathrm{r}$ Product Moment dalam tabel $(0,619>0,576)$. Dengan demikian hipotesis nihil (Ho) ditolak, sedangkan hipotesis alternatif (Ha) yang diajukan diterima. Hasil analisis data menunjukkan bahwa nilai $r$ hitung lebih besar dari pada nilai $r$ Product Moment dalam tabel $(0,619>$ 0,576), yang memiliki makna bahwa ada korealsi antara program pelatihan tata rias kecantikan dengan sikap wirausaha warga belajar di LKP Kartika. Adapun tingkat interpretasi nilai hubungan program pelatihan tat arias kecantikan dengan sikap wirausaha dapat dilihat dalam tabel sebagai berikut:

Tabel 6. Interpretasi Nilai $r$

\begin{tabular}{|c|c|}
\hline Besarnya nilai $\mathbf{r}$ & Interpretasi \\
\hline Antara 0,800 sampai dengan 1,000 & Sangat Kuat \\
\hline Antara 0,600 sampai dengan 0,800 & Kuat \\
\hline
\end{tabular}




\begin{tabular}{|l|c|}
\hline Antara 0,400 sampai dengan 0,600 & Cukup Rendah \\
\hline Antara 0,200 sampai dengan 0,400 & Rendah \\
\hline Antara 0,000 sampai dengan 0,200 & Sangat rendah \\
\hline
\end{tabular}

Dari table diatas, dapat disimpulkan bahwa program pelatihan tata rias kecantikan dengan sikap wirausaha warga belajar di LKP Kartika memiliki hubungan yang "Kuat".

Pelaksanaan program pelatihan pada bidang tata rias kecantikan yang baik, maka akan berpengaruh pula pada peningkatan sikap wirausaha warga belajar. Karena dengan bimbingan dan pelatihan yang baik yang dilakukan oleh instruktur secara intensif serta didukung oleh sarana dan prasarana yang memadai, akan mampu mengembangkan bakat dan minat peserta pelatihan agar memiliki motivasi dan semangat serta kepercayaan diri yang tinggi untuk berwirausaha. Adapun hasil penelitian ini sejalan dengan penelitian lainnya (Anjani \& Darojatun, 2019; Pratiwi, 2018; Wahyu \& Rizka, 2018) yang menjelaskan bahwa pelaksanaan program pelatihan keterampilan dengan pengelolaan yang profesional akan berdampak pada sikap wirausaha warga belajar yang meliputi percaya diri, berorientasi pada tugas dan hasil, pengambilan resiko dan suka tantangan, kepemimpinan, keorisinilan, dan berorientasi ke masa depan (Dewi et al, 2016).

\section{Kesimpulan}

Berdasarkan hasil perhitungan rxy yang diperoleh dalam penelitian ini adalah 0,619, sedangkan nilai $r$ Product Moment dalam tabel dengan taraf signifikansi 5\% dan $\mathrm{N}=12$ adalah 0,576. Sehingga nilai $r$ hitung lebih besar dari pada nilai $r$ Product Moment dalam tabel $(0,619>0,576)$ dengan kesimpulan ada hubungan antara program pelatihan tatarias pengantin dengan sikap wirausaha warga belajar di di lembaga pendidikan nonformal LKP Kartika.

\section{Saran}

Adapun saran yakni (1) bagi pengelola kursus dan pelatihan diharapkan selalu melakukan pembinaan secara terus menerus dari pelatihan yang diselengarakan sebagai bentuk inovasi program serta perlu ada tindak lanjut untuk pendampingan kewirausahaan bagi warga belajar, (2) bagi instruktur agar tetap melakukan inovasi baik dalam materi dan media serta metode pembelajaran orang dewasa, dan (3) bagi warga belajar agar selalu terus bersemangat dalam belajar dan berkarya demi terciptanya kesamaan gender dan terciptanya perempuan yang terampil dan berbakat.

\section{Daftar Pustaka}

Arikunto, Suharsimi, (2010). Prosedur Penelitian Suatu Pendekatan Praktek. Jakarta: Rineka Cipta

Anjani, T. R. D., \& Darojatun, I. (2019). PROGRAM PELATIHAN KETERAMPILAN TATA RIAS PENGANTIN DALAM UPAYA PENINGKATAN PENDAPATAN MASYARAKAT (Studi kasus Penelitian pada Peserta Didik di LKP HENNY'S Kota Cimahi). Comm-Edu (Community Education Journal), 2(2), 153-161.

Ciputra. (2007). Pendidikan Kewirausahaan Untuk Menyelesaikan Masalah Kemiskinan dan Pengangguran di Indonesia. Jakarta.

Dewi, N. L. A., Suwena, K. R., \& Sujana, I. N. (2016). Pengaruh Sikap Kewirausahaan Terhadap Kemampuan Mengelola Usaha Pada Peserta Program Mahasiswa 
Wirausaha (Pmw) Undiksha Tahun 2015. Jurnal Pendidikan Ekonomi Undiksha, 7(2).

Nurdin, A. (2016). Pendidikan Life Skill Dalam Menumbuhkan Kewirausahaan Pada Peserta Didik Pendidikan Nonformal Paket C. Tarbawi: Jurnal Keilmuan Manajemen Pendidikan, 2(02), 109-118.

Pratiwi, N. T. D. (2018). PELATIHAN TATA RIAS WAJAH DALAM UPAYA MENUMBUHKAN KEMANDIRIAN PESERTA DIDIK DI LKP MUTIARA AINI JOMBANG. $J+$ PLUS UNESA, 7(1).

Rizka, M., \& Zulkipli, Z. (2017). Efektivitas Implementasi Pelatihan Keterampilan Kerja Dalam Meningkatkan Kompetensi Calon Tenaga Kerja.Jurnal Kependidikan: Jurnal Hasil Penelitian dan Kajian Kepustakaan di Bidang Pendidikan, Pengajaran dan Pembelajaran, 3(1). doi:https://doi.org/10.33394/jk.v3i1.472

Sugiyono, (2014). Metode Penelitian Pendidikan (Pendekatan Kuantitatif, Kualitatif, dan $R \& D)$. Bandung: CV. Alfabeta.

Sujarweni, V. W. (2008). Belajar Mudah SPSS untuk Penelitian. Yogyakarta: Global Media Informasi.

Sumiyanty, E. S. E., Suharyani, S. S., \& Rizka, M. A. R. M. A. (2018). HUBUNGAN PROGRAM TAMAN BACAAN MASYARAKAT (TBM) TERHADAP MINAT MEMBACA WARGA BELAJAR KEAKSARAAN FUNGSIONAL DI PKBM CERIA. Transformasi: Jurnal Penelitian dan Pengembangan Pendidikan Non Formal Informal, 4(1).

Sya'i, S., Rizka, M., \& Gunawan, I. (2021). Studi Korelasi Antara Pendidikan dan Pelatihan (Diklat) Tutor PAUD dengan Peningkatan Kompetensi Mengajar. Jurnal Paedagogy, 8(3), 351-356. doi:https://doi.org/10.33394/jp.v8i3.3793

Soemanto Westy. (2002). Pendidikan Wiraswasta. Jakarta: Bumi Aksara

Tamba, W., Rizka, M., \& Andriani, I. (2020). Implementasi Pendidikan Masyarakat Melalui Pemberdayaan Perempuan Berbasis Life Skill Education. Jurnal Paedagogy, 7(3), 237-243. doi:https://doi.org/10.33394/jp.v7i3.2745

Winandi, W., \& Rizka, M. (2018). Implementasi Pelatihan Lifeskill untuk Meningkatkan Motivasi Berwirausaha Wanita Tuna Susila di Panti Sosial Karya Budi Rini. Jurnal Kependidikan: Jurnal Hasil Penelitian dan Kajian Kepustakaan di Bidang Pendidikan, Pengajaran dan Pembelajaran, 4(1), 109-118. doi:https://doi.org/10.33394/jk.v4i1.908 